\title{
RHYNCHONELLA BOUETI
}

SIR,- It was with considerable interest that I read W. G. Aitken and W. S. McKerrow's paper (Geol. Mag., lxxxv, 1948, 19-32) on the variation of the rhynchonellids from the Boueti Bed at Langton Herring. Such " Variation Studies " are, of course, of great importance in dealing with the Coal Measure lamellibranchs, and the authors are to be congratulated on applying the technique to another group of fossils.

During a visit to the Dorset coast by the Geological Society's 1947 Students' Tour under the direction of Mr. P. C. Sylvester-Bradley and Dr. W. D. Evans, Mr. R. H. Hoare collected a similar set of

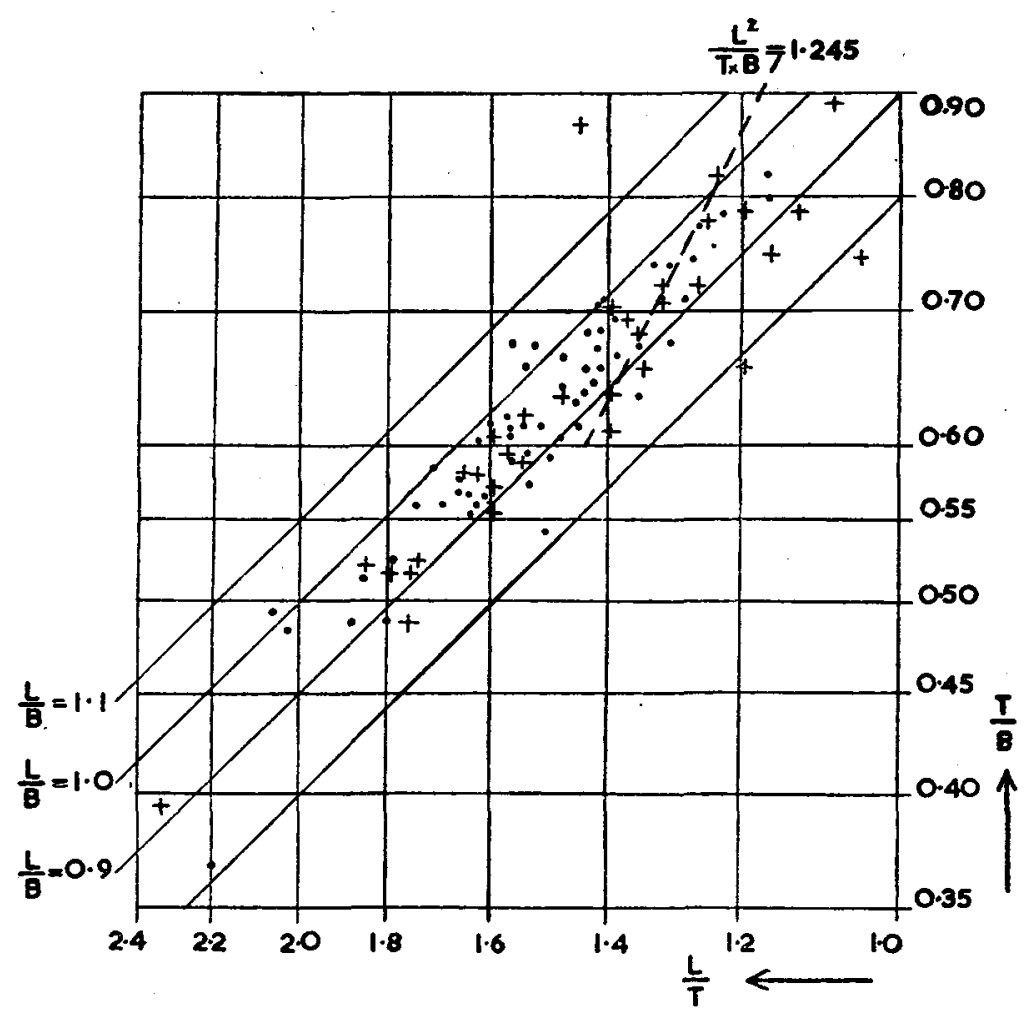

Scatter diagram connecting $\frac{L}{T}, \frac{T}{B}$, and $\frac{L}{B}$ for a community of rhynchonellids from the Boueti Bed, Langton Herring.

- shells collected by W. G. Aitken and W. S. McKerrow. (See Text-fig. 10, p. 29.)

$+=$ shells collected by R. H. Hoare. 
rhynchonellids from the same locality. These specimens, too, fit exactly the variation series recognized by the authors; this confirms that their collection is, on the basis of the external characters of the shells, fully representative of the rhynchonellid community of that locality.

The authors' text-fig. 10 is indeed a valuable diagram for there is a close correspondence between it and the variation diagram obtained by a subjective analysis of the shells ; but the statement on page 26 that : "The position of each point [in text-fig. 10] thus depends on the relative values of the thickness [T], length [L], and breadth [B] of the shell," may be queried. The present writer would point out that the position of each point in the diagram depends only qualitatively on the relative values of $L, T$, and $B$. Quantitatively the points are determined by the relative values of the ratios $L / T, T / B$, and $L / B$.

Palaeontologically, $\mathrm{L}, \mathrm{T}$, and $\mathrm{B}$ are " independent variables", but when the values of $L / T(=x$ say), and $T / B(=y)$, and $L / B$ are plotted it is these ratios that, strictly speaking, are the variables. Since these three ratios are connected by the expression $L / T \times T / B$ $=\mathrm{L} / \mathrm{B}$, only two of them are " independent " variables. Thus textfig. 10 actually shows only the relation between two independent variables. In other words each point in the diagram is defined precisely by the values of $L / T$ and $T / B$, the value of $L / B$ being determined automatically in accordance with the expression $\mathrm{L} / \mathrm{T} \times \mathrm{T} / \mathrm{B}=\mathrm{L} / \mathrm{B}$ as given above.

Consequently the same "scatter pattern" as in text-fig. 10 can be obtained by plotting $L / T$ and $T / B$ along ordinary $x$ and $y$ axes. If such a plot is made on an arithmetic scale the pattern differs slightly and the line $\mathrm{L}^{2} / \mathrm{T} \times \mathrm{B}=1 \cdot 245$ is a curve, the equation to which is $y=1 \cdot 245 x^{-2}$. When, however, the plot is made on a logarithmic scale, as is done by the authors, this line becomes rectilinear and the scatter pattern obtained is that of text-fig. 10 .

In this way the complications involved in representing graphically the variation in this community of rhynchonellids are avoided. The diagram enclosed shows the results of such a plot; also shown on this diagram are the values for some of the shells collected independently from the same locality by $\mathbf{R}$. H. Hoare.

ROBERT K. BLundell.

Department of Geology,

UNIVERSITY COLlEGE,

NEWPORT ROAD,

CARDIFF.

8th March, 1948. 
SIR,-While not wishing to criticize an excellent piece of work on the rhynchonellids of the Boueti Bed in your January number by Messrs. Aitken and McKerrow (with whom I have unfortunately lost contact since accompanying them on the field party on which the material in question was collected), I do feel that some additional information would greatly increase the value of the paper.

The term community implies a strictly contemporaneous existence in a very restricted locality and the palaeontologist who uses it is making a very exacting claim for his work. The material from a random collection from the shore at Langdon Herring does not at first sight appear to constitute a community, though it might approximate to one if $R$. bouet $i$ is substantially absent from the other strata associated with the Boueti Bed and if the front on which the material was collected was sufficiently restricted.

It would be very interesting if this " community " can be established to know, too, something about the lithology and associated fauna, since a community is in complete ecological equilibrium; that is to say equilibrium with its physical and biological environment. Is there any chance of mixing of forms from a different environment by sampling or by transportation at the time of deposition? Do, for example, separate, worn, or broken valves occur and do the Polyzoa throw any light upon the environment? It is again emphasized that in the opinion of the writer the paper remains of great value for its method of treatment and this letter is merely a request that the authors " give us more". The results obtained would seem to be of much greater interest if they could be augmented by palaeoecological data as well.

F. W. Beales.

McMaster University, Canada. 12 th March, 1948.

\section{CAUSES OF ICE AGE}

SIR,-Geologists and others who concern themselves with past climates, and particularly with those of Pleistocene times, have reason to be indebted to Dr. Fuchs and Mr. Paterson for their illuminating contribution to the vexed problem of the inception and development of an ice age, and for the sound contention that the Glacial Period has no single cause, but resulted from a combination of circumstances which could hardly have arisen except during a period of orogeny (Fuchs and Paterson, 1947).

That no one factor is alone responsible for the advent of the great glaciations that have punctuated the geological record has long been recognized; and Brooks, while stressing the importance of con- 